\title{
Facing the digital divide in a participatory way - an exploratory study
}

\author{
Elaine C. S. Hayashi ${ }^{1}$, M. Cecília C. Baranauskas ${ }^{2}$ \\ ${ }^{1}$ Instituto de Computação - UNICAMP, Brazil, elaine.hayashi@ gmail.com \\ ${ }^{2}$ Instituto de Computação \& NIED - UNICAMP, Brazil, cecilia@ic.unicamp.br
}

\begin{abstract}
One of Brazilian's grand challenges in computer science research concerns a "Participative and universal access to knowledge for the Brazilian citizen". In order to develop design solutions to address this challenge, we first need to understand these citizen's abilities and the context in which they are immersed. For that, we have been conducting practices actively involving a group of representatives of the diversity of users we have in the population. This paper presents the first results of this investigation, pointing out some lessons learned so far regarding the relationship they have with Information and Communication Technology (ICT) and how they make sense of different models of interaction to accomplish a simple task related to the exercise of citizenship. Among other findings, we were able to notice how their previous experience reflects on their behavior and the benefits of using an avatar in future systems.
\end{abstract}

Keywords: digital divide, accessibility, participatory design, universal design

\section{Introduction}

According to Drucker (1993), the main resource of our society in the future will be knowledge. Terabytes of information are digitally available and this amount grows everyday, but it is not everyone who is able to access it. The information is there and the means to spread it are also available through Information and Communication Technology (ICT). Some authors say the barriers to access knowledge do not have a technological nature, but rather social and economical ones (Varian, 2005), (Information, 2006); illiteracy for example is one of these barriers. In the reality of many developing countries, we have to consider both types of illiteracy, the literal and the digital illiteracy.

The Unesco's World Report (UNESCO, 2005) states that ICT creates conditions for the emergence of knowledge societies and these societies are a source of development for all. But for this society to arise, it is necessary to bridge the gap and diminish digital divide. In order to achieve that we need to develop systems that can be accessed by everyone. As stated by Shneiderman (2000), universal access initiatives should address at least three main issues: user diversity 
(user with different skills, knowledge, age, gender, disabilities, literacy, etc), technology variety (support to a broad range of hardware, software and network access) and gaps in user knowledge (the difference between what users know and what they should know).

In a country that has continental dimension and 189 millions of inhabitants, the variety of its population could be huge. While $86 \%$ of Brazilian's adult population is considered literate (WorldBank, 2006) only 26\% is actually capable of understanding a simple written text (Ribeiro, 2003), 14\% has some kind of physical disability and $79 \%$ (of the population with 10 years old or more) have never accessed the internet (IBGE, 2005).

In spite of the supremacy of some computer hardware and software, it is necessary to think of solutions that can be accessed through any platform, i.e., that can be reachable by anyone. But much more than that is the challenge of designing interface and interaction solutions to reach the diversity of the population.

The Brazilian Computer Society's (SBC) challenge \#4 dares us to think of and research about "Participative and universal access to knowledge for the Brazilian citizen". This is one of the five Grand Challenges in Computer Science Research for the years 2006 - 2016 that resulted from an event in 2006 sponsored by SBC (SBC, 2006).

Today there are public and private initiatives in the country to provide universal computer access, but most people do not make sense of possibilities brought by computers and internet. What kind of system could be developed that would work as a source of knowledge and would be appealing to the Brazilian's less favored population?

According to Melo and Baranauskas (2006), the accessibility recommendations are not enough to handle all the complexity that the Design for all demands in the scenario we have. To start facing the challenge, we decided to work directly with the user, who should have an active role in the design process. Participatory Design (PD) methods, tools and techniques have been successfully adopted (Rocha and Baranauskas, 2003), (Kensing and Blomberg, 2004),(Muller, 2002) in this sense: a design with, for and by the user (Lanzara, 1983). Including the user in the design process is vital to make sure we are creating systems that make sense and that are part of the users' context of life.

At the same time, we have noticed in recent years the amazing success that sites like Orkut are having in Brazil especially with the young people. Ramachandran et al. (2007) states that it is clear that "social networks play a dominant role in influencing the adoption and the use of ICTs". That gives us a hint that online social networks may be the means we were looking for to promote the digital culture in this population.

Within this context of universal and participatory access to information, we have been conducting participatory practices with a selected group of people in Campinas - a city in São Paulo State - as part of a project of a broader scope in which the objective is to develop online social networks that are inclusive and meaningful for Brazilian citizens. In this paper, we describe preliminary findings regarding activities we started within this community to investigate possible 
design solutions. The goal in the activities we are going to report in this paper was to recognize and better understand the relation this group has with ICT, how they interact and make sense of it. We also investigated how they respond to the different forms of media: text, sound and images. As a result, we present here preliminary findings and first lessons learned from this work.

The paper is organized as follows: the next section gives details about the scenario and group of participants in the study, describing the practices carried out. Section 3 presents preliminary results of analysis. Section 4 discusses some lessons learned from this experience and Section 5 summarizes a conclusion.

\section{The Participatory Study}

\subsection{Scenario and Subjects}

The study we are conducting takes place at Vila União, a suburb area in Campinas considered class D and $\mathrm{E}$ in terms of socio-economical indicators. A kind of "TeleCenter" hosts the activities; it is a physical space where several community initiatives for digital inclusion associated to the federal and local governments take place; Casa Brasil, Centro de Referência da Juventude (CRJ) and Jovem.com are some of those programs. Casa Brasil is a national initiative to promote digital inclusion. It is a public space where people have free access to a TeleCenter, library and basic computer courses. The same building also houses the Jovem.com and $C R J$ (Youth Reference Center). Both are projects from the city of Campinas and they all have the same objective: bring digital inclusion to the community as a means of opening the doors for social inclusion (Casa Brasil).

Within that community, we formed a group of 10 to 15 people representing part of the diversity we have in our population in its cultural, social and economical aspects. We named this group Cenário Estrela (or Cenário*). Inspired by the numbers from the IBGE (Brazilian Institute of Geography and Statistic) we took percentages of the population in terms of gender, age range, literacy and income per family. We used these numbers to invite people from Vila União to take part of Cenário*. We counted on a partnership with the local Secretary for

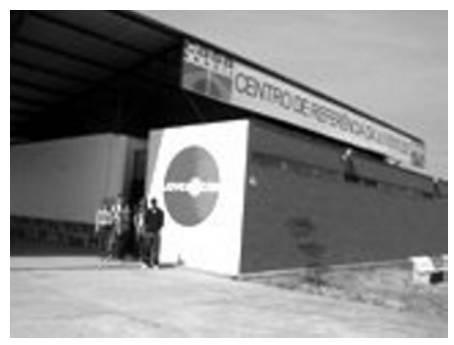

Figure 1 A view of Casa Brasil Citizenship from the City Hall to help us form this scenario. Casa Brasil is hosting the Cenário* and our team of researchers in regular practices twice a month. Figure 1 illustrates this place.

On the first day of activities, we had 10 participants from the Cenário*. This group had 3 men and 7 women. We have attempted to have a group composition reflecting the less favored in terms of access to technology. For example, for 
ages around 30's the percentage of participants do not reflect the proportion we have in the country, as they are the part of the population who are most likely to have access to computer and internet, either at work or at college. Because our focus is to study the ones whose relationship with technology is lower or none we have chosen to maintain less people from the 30 to 49 age range. Nonetheless the point of view of the digitally literate still exists in the group and it is important when we think of the Design for All (two participants are well familiar with technologies).

The population of this Cenario* is very talkative and sincere, which significantly contributes for the success of our activities. They are able to express their thoughts and desires and are always willing to contribute and participate. Just as the Brazilian reality itself, the group is very heterogeneous: some of them had never touched a computer before while others are attending college. Despite de diversity, all members get along very well in a healthy and democratic atmosphere. Also, their commitment to the activities has contributed to the quality of our achievements.

\subsection{Method and Practices}

Before meeting the people of Cenário*, the group of researchers met to discuss and design the activities. The preparation stage is an important part of the process as it makes clear what the objectives are and how they should be achieved. In this preliminary work, all artifacts that are needed are designed and constructed and tasks are reviewed and distributed among researchers. Rehearsals may also be necessary; when you put yourself in the place of the user in the activities you are able to anticipate problems and also you may realize what other props might be needed throughout the practice.

The next step after the preparation is the activity execution itself. The first time with the users required a quick individual presentation and elucidation about the project and its purposes and goals. During the activity, all interactions were video taped and all conversations were recorded using MP3 devices. This has been done in accordance with the Brazilian rules of ethics in research. All the recordings were properly edited and saved to be used in the analysis, and are now part of a rich material that is of great importance for the research.

The analysis phase consisted of examining all material in order to understand the findings and derive preliminary conclusions regarding the objectives of that stage. The activities described in this article are part of an initial stage of design when we want to get acquainted with users' relationship with ICT. This accounts for the "gaps in user knowledge", an issue mentioned before, that is one of the three challenges mentioned by Shneiderman (2000) in gaining universal usability for Web-based services. Being aware of what users know is essential for development as it allows us to understand the users' context, which is a basic requirement of user-centered design (Minocha, 1999).

For this initial stage of the study we considered starting with the Story Telling technique (Muller, 2002) followed by a practice we designed to investigate the 
accomplishment of a common task (related to getting a second via of an id card) through different media. In the next sections we describe each activity and its preparation.

\subsubsection{StoryTelling}

The StoryTelling Workshop is a PD technique usually applied in the early stages of design in order to help the designers to identify and clarify the design problem (Rocha and Baranauskas, 2003). According to Muller (Muller, 2002), stories and storytelling in participatory work can function in at least three ways: 1 . understand the product or service (when told by the end-user); 2. present what a designed service will do (when told by the designers) or 3 . used as triggers for conversation. In our context, this method worked not only as a conversation startup, breaking the ice on the first day with the users but also helped us understanding the users' context.

With all participants gathered in a circle, each one told the group one case of success and one case of failure in using any type of information or communication technology. Simple examples of misuse of daily appliances like cell phones and digital alarm clocks were enough to make the group recognize common difficulties with technology in general. This identification added for the cohesion of the entire group. Knowing that all have abilities and difficulties made the group fell comfortable in sharing and freely participating in the activities without fear or constrain.

Activity preparation. The StoryTelling does not require much preparatory work. No extra materials besides the chairs arranged in a circle in the room and badges for the participants are necessary. The only action proposed beforehand, was that the researchers would think of simple cases of success and failure of their own, so that they would be able to share their experiences too, especially if the users would not feel comfortable to start with their stories.

\subsubsection{Simulating a Service in Different Media}

This activity aimed to investigate how comfortable the members of Cenário* feel getting information from different types of communication channel. An imaginary situation was proposed to the group: "Paula, a married woman, 25 years old had lost her identification card and she does not know what she needs to order a new one". One of the researchers played the role of Paula and she told the Cenário*
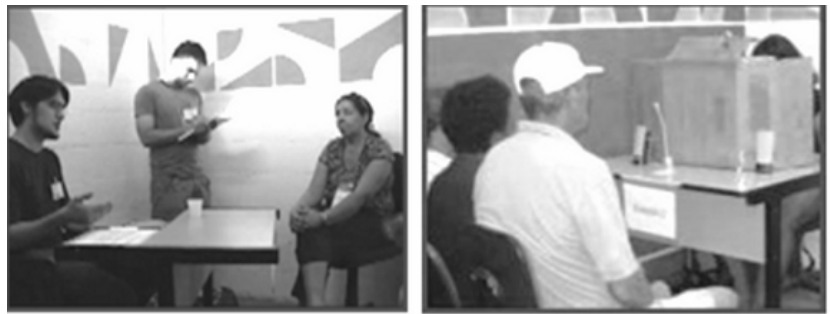

Figure 2 Interaction at S1 (left) and S2 (right). about her problem. The group was supposed to help her and find out what were the necessary documents that she needed. For that, they were divided into four groups and each was taken into a 
different station: Station 1 (S1) an information booth simulation; Station 2 (S2) an Automated Response Unit simulation; Station 3 (S3) an iconic (graphical) computer screen simulation; and Station 4 (S4) a textual computer screen simulation. After talking to Paula at station S5 to present her with the answer, all groups got together again and shared their experiences. The stations are briefly described below.

S1 - Information booth simulation. Here the users interacted directly and personally with an attendant who followed a script to give the users all the information they would ask him for. This script was previously prepared and the desk had paper and pen in case they wanted to take notes.

S2 - Automated Response Unit (ARU) simulation. This station simulated an ARU: a call center service where the user interacts with a machine. ARU provides audible responses (pre-recorded sentences) to digital inquires from the user, usually by telephone.

The audible information on S2 came from a laptop computer that was kept hidden from the users behind a box. This box was built so that the audio source would be put in evidence, preventing the users from having any visual contact with the source of information.
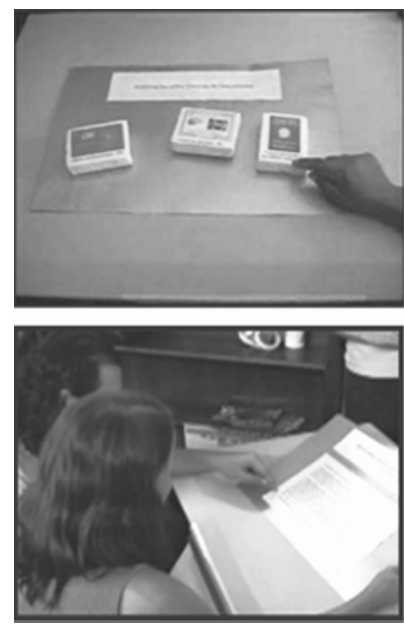

Figure 3. Images (S3 above) and text (S3 below).

S3 - Iconic computer screen simulation.

Cardboard pieces were make believe computer screens. With these artifacts the users were able to obtain the information from images and concrete objects displayed under a structure similar to the ones found in most of the internet sites. The researcher would hand in a cardboard at a time, accordingly to the users' choice, as if they were screens that came after users' mouse click.

S4 - Textual computer screen simulation. The same cardboard pieces were prepared for S4 as for S3, only that here there were no images, but only text. All the information was written and glued into the cardboards.

S5 - Paula's place. This was the station where all groups went after they were done with their tasks. Paula waited here for them to return and tell her what documents she would need in order to apply for a new identification card. At the end of each report, Paula asked the users two new questions: whether the copies

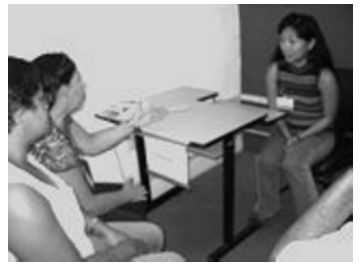

Figure 4. Results being delivered at S5. could be regular ones or the original documents were needed and if her husband, who had also lost his id card, would need the same documents.

Activity Preparation. Before going to Casa Brasil for the activities, all material was thought and prepared. For S1 there was the script for the help attendant, the cardboards with information for S3 and S4, and the pre-recorded sentences for S2. The content for all stations were basically the same: the list of documents 
necessary for acquiring different cards. This content is a simplification of what we found in our government Portal regarding this type of service.

Cardboards were chosen for this activity for the same reason most designers make use of paper prototyping: it is inexpensive and so familiar that users can feel more comfortable and not afraid of using (Rocha and Baranauskas, 2003), (Chand et al., 2006) them as they could be in front of a computer screen.

For S3, the cardboards were prepared as to offer as many images as possible and less written information. On the other hand, the screens simulations for S4 were text only. Both intended to deal with exactly the same information content.

The sentences recorded for S2 were saved on a laptop computer, but they actually had a manual process of activation. One of the researchers had to control the reproduction of the audio files accordingly to the users' response. Both laptop and researcher were hidden from users' sight through a box installed between them.

\section{Preliminary Results}

\subsection{Warming up with Story Telling}

A rich material resulted from this practice. All users had something to tell us and it all helped us to understand and identify abilities and barriers that stand between users and technology.

Four out of our 10 participants had an experience to share about the use of cell phones. Even knowing that the device has more features than just making and receiving calls, most people are limited to these functions. It is interesting to notice that cell phones are no longer restricted to the upper levels of the socialeconomic pyramid. According to IBGE (IBGE, 2005), 37\% of our population (aged 10 years old or more) have a cell phone for personal use and most people have more than one unit, as per the National Telecommunications Agency (Anatel)`s data (Anatel, 2006), which shows that there are more than 120 million units supplied with mobile communication services. Mobile phones are also one of the preferred means of communication for deaf people in Brazil.

Other four participants reported their story of familiarity/unfamiliarity with computers. They all seem to understand that computers and internet access are a powerful source of knowledge but it seems that the elder consider these technologies something for the younger generation. Most people of age 50 or more think they do not have the skills to perform simple tasks in DVDs, mobiles or computers.

From this activity we can say that the StoryTelling workshop was an efficient mechanism of bringing people closer in the sense of knowing they all have something in common to share. Besides being able to recognize users familiarity with ICT, we were also capable of identifying vocabulary and metaphors used by Cenário*`s population. Their culture was also put in evidence, showing us a reality 
that we were not aware of. For example, one of the users mentioned that her mother did not allow her picture to be displayed on a social network website because it would reveal to strangers her bank account password. The concern about money was also noticed when another participant told us of the day when she did something wrong while using her telephone and she believes that a touch of a wrong button on the telephone made her loose all her telephone credits at once.

\subsection{A Simple Task in Different Interaction Media}

In average it took the groups about ten minutes to finish their tasks. The fastest, and by the way also the most effective one, was the group who worked at S1 with the help attendant. They got all the information in 3'38', The group to spend the longest time interacting with his station was S2: they needed 21'06' to deal with the sound device. The users who went to $\mathrm{S} 1$ were the only ones to bring to Paula the correct list of documents, although no group was able to correctly answer Paula's extra questions.

None of the groups took written notes of the information received; they all seemed very confident on the answer and had in memory the list of documents.

In $\mathrm{S} 1$, the group that interacted with a real person was able to maintain a regular conversation with the source of information. One of the members of this group mentioned to the attendant that Paula had her ID card stolen, which was immediately corrected by another participant. Paula's introductory talk was only oral.

Two of the three users on S2 left the station very confused and aware of the fact that they did not have the correct answer for Paula. The options from the audio simulation were too long for them to keep close attention. One of the participants from this group demonstrated very good memory and focusing capacities. She was able to specify details like how the picture for the new ID card should look like (front picture, recent and in plain background), and even named the documents that Paula should present in case she was single (married and single persons need different certificates)

It was interesting to note how a previous experience from a user that participated on S3 interfered in the task execution. She herself had had the same problem of losing her identification card. The difference was only that she is widow. By the time she experienced this situation though, she had trouble finding one of the necessary documents, which was her jobholder card ${ }^{1}$. One of the first screens presented to the users has a menu with three options. They are pictures of three different documents and the users were supposed to choose the one corresponding to the doc they had lost. She (with her group colleagues) promptly pointed to the jobholder card instead of the ID card and a sequence of different

\footnotetext{
${ }^{1}$ In Brazil, most employees have a document that looks like a passport, where all previous employers register the information about the job held by that person during the period that he or she worked for them.
} 
screens followed. They only noticed the misjudgment when the list of required documents appeared with the lost ID card on it. The result that the group presented to Paula was not correct, and they even mentioned a document that does not exist: a single's certificate (meaning the person never got married. Actually she meant birth certificate, which does exist).

The text-only material from S4 worked smoothly and they were able to easily identify the right path through the screens. One of the participants was very attentive and read everything thoroughly. They did not take any notes though, and at the end they provided Paula with incomplete information.

\subsection{Discussion and Lessons Learned}

\subsubsection{Users and their previous experiences}

In different moments we could observe how users' prior experience can inadequately influence tasks performance.

Each life experience is unique and when we talk about a country with continental proportions like Brazil, we can count a variety of about 189 million different backgrounds. We can not prevent users from bringing their previous knowledge to the task, quite the contrary, but we must think of ways to make it in their benefit. Making the system simple in structure (Norman, 1990), minimizing distraction and interruptions is not enough.

\subsubsection{Real life metaphor}

The team to present the best result participated on a station where a real person informed the procedures to request a new ID card. In that situation, users' memory and attention were stimulated by visual aids (the attendant's complexion), audio (attendant's voice) and synesthetic (attendant's body expression and movement). That suggests us that redundant or complementary information are of great value when aiming for an interaction that resembles more like a human-human communication instead of a human-computer one (Reeves et al., 2004). As designers we must be careful though, not to overlap too much multimedia information as it could lead to a contrary effect (Reeves et al., 2004),(Leahy et al., 2003); it could even cause problems in memorization or learning (Jamet and Le Bohec, 2007).

One metaphorical embodiment of all this multimodal complexity could be that of an avatar. This idea came up from a conversation with a user who stated that the system should be like a "Geraldo online" (in reference to the name of the person who played the role of the attendant on S1). Indeed, this metaphor was taken in a prototype for a subsequent activity. The avatar would represent an attendant that gives all necessary information. According to Marcus (1998), the use of metaphors in interfaces can offer numerous advantages: the familiarity will require less training from users; it can add appeal; it may increase ease of learning; it can assist to a more direct communication; and cultural associations of user 
communities could be made. Still needs further investigation the implications of the anthropomorphic nature of the avatar for this population.

\subsubsection{Multimodal interaction}

The ARU simulation did not have a good acceptance in our experiment, but the use of auditory menus could help not only the visual impaired users but also the illiterate. Experiments on cell phones showed that such a menu is feasible (Eiriksdottir et al., 2006) and another study performed with blind children evidenced that sound at the interface can enhance memory and learning (Sánchez and Flores, 2004).

Graphic representations help users with subnormal vision, the illiterates, or even the hearing-impaired users. But alone, the images may not make sense or could be misleading, as we saw on S3, when sometimes more text was needed in order to complete the information that the picture provided.

Images and sounds are very helpful to add meaning to the context. They provide users with more resources for them to build they own reading strategies. This greatly facilitates understanding, but alone (i.e. only images or only sound) they are very less powerful.

\subsubsection{The common ground}

As heterogeneous as they can be, a group of users will always have something they share. It may be a point where they all agree or basic needs they all want to be fulfilled. There can be many different backgrounds that lead to different ways of thinking, but even so we can find more invariants than we could imagine. By focusing in these invariables we can move towards the Design for All. In the experiments we have conducted so far we saw that this recognition of the common ground is more easily noticed when we work directly with the user, in a participatory way.

\subsubsection{Digital divides}

From the StoryTelling activity we learned that even though they may not use ICT in its full capacity, the Cenário* is aware of the ICT' existence and its utility. Their concern relies mostly on the fear of loss, especially that of money. We perceived that during the StoryTelling activity, when they reported cases of losing credits due to misuse of the device or even a mystical relationship between having a picture shown on a web page and the bank account password being broadcasted. So, besides all initiatives for making technology available to the whole population, it is necessary to think of systems that would be so relevant that the contribution brought by its use would be greater than their fears or beliefs. Participatory practices contribute, may be in a small proportion, to the process of eliminating some of the myths by having the user actually use and see how the technology works and how they can benefit from it. 


\section{Conclusion}

At the same time that ICT creates conditions for the emergence of knowledge societies, it can be a source of digital divide. In a developing country that has continental dimension and millions of inhabitants, the variety of its population is huge. The emergence of a knowledge society as suggested by UNESCO demands development for all. In this paper we address some issues regarding the challenges of making systems that can be accessed by everyone in these societies.

We presented how we are facing the challenge by describing the participatory approach we are using, illustrating it with the first practices in the Cenário*, with a group of users formed as to represent part of the diversity we have in the Brazilian's population, with its vast social, cultural and economical differences.

These activities were part of a project that aims at the development of inclusive social networks that make sense for people as a way of promoting their own life conditions by interacting in the digital world. The paper discusses the preliminary results and lessons learned from the activities designed for this study. The next steps include a more in deep study of the vocabulary mostly used by our target public and a test on the acceptance of some ideas taken from this present study, like the use of real life metaphors (avatars and voices) in informational web sites.

Acknowledgments. This project is funded by Microsoft Research - FAPESP Institute for IT Research. The authors thank all colleagues from NIED, InterHAD, Casa Brasil and IC Unicamp.

\section{References}

Anatel. http://www.anatel.gov.br (2006). Accessed 12 Feb 2008.

Casa Brasil. http://www.casabrasil.gov.br. Accessed 12 Feb 2008.

Chand, A. and Anind, K. D.: Jadoo - a paper user interface for users unfamiliar with computers. In CHI 2006, Montréal (2006).

Drucker, P.: Sociedade Pós-Capitalista. Pioneira, São Paulo. Translated from the original "The Post-Capitalist Society" (1993).

Eiriksdottir, E., Nees, M., Lindsay, J., Stanley, R. : User Preferences for Auditory Devicedriven Menu Navigation. In Proceedings of the Human Factors and Ergonomics Society 50th Annual Meeting (2006).

IBGE (Instituto Brasileiro de Geografia e Estatística). http://www.ibge.gov.br/home/ (2005) Accessed 12 Feb 2008.

Information Society: the Next Steps. In Development Gateway Special Report. Available at http://topics.developmentgateway.org/special/informationsociety/index.do (2006) Accessed 12 Feb 2008.

Jamet, E. and Le Bohec, O.: The effect of redundant text in multimedia instruction. In Contemporary Education Psychology. Vol. 32, issue 4. Elsevier (2007).

Kensing, F. and Blomberg, J.: Participatory Design: Issues and Concerns. In CSCW, Springer, Neatherlands (2004). 
Lanzara, G.F. The Design Process: Frames, Metaphors and Games. In Briefs, U. \& Ciborra, C. \& Schneider, L.: Systems Design For, With and By the User. North-Holland Publishing Company, Amsterdam (1983).

Leahy, W., Chandler, P. and Sweller, J.: When Auditory Presentations Should and Should not be a Component of Multimedia Instruction. In Applied Cognitive Psychology (2003).

Marcus, A.: Metaphor Design in User Interfaces. In Journal of Computer Documentation (1998).

Melo, A. M. and Baranauskas, M.C.C.: An Inclusive Approach to Cooperative Evaluation of Web user Interfaces. ICEIS, vol 1, p. 65 - 70 (2006).

Minocha, S.: Requirements Development in User-Centred System Design. In IEE Colloquium on Making User-Centred Design Work in Software Development (1999).

Muller, M.J.: Participatory Design: The Third Space in HCI. IBM Watson Research Center. Technical report (2002).

Norman, D. A.: The Design of Everyday Things. Currency and Doubleday, New York (1990).

Ramachandran, D., Kam, M., Chiu, J., Canny, J. and Frankel, J.: Social Dynamics of Early Stage Co-Design in Developing Regions. In Proceedings of the SIGCHI conference on Human factors in computing systems. California (2007).

Reeves, L.M., Reeves, L.M., Lai, J., Larson, J.A., Oviatt, S., Balaji, T.S., Buisine, S., Collings, P., Cohen, P., Kraal, B., Martin, J.C., McTear, M., Raman, T.V., Stanney, K.M., Su, H., Wang, Q.Y.: Guidelines for Multimodal User Interface Design. In Communications of the ACM. Vol 47, no 1 (2004)

Ribeiro, V. M.: Letramento no Brasil: reflexões a partir do INAF 2001. Global, São Paulo (2003).

Rocha, H.V. and Baranauskas, M.C.C.: Design e avaliação de Interfaces HumanoComputador. NIED/UNICAMP, São Paulo (2003).

Sánchez, J., Flores, H.: Memory Enhancement through Audio. In ASSETS'04. ACM, Georgia (2004).

SBC The Brazilian Computer Society (2006). Grand challenges in computer science. http://sistemas.sbc.org.br/ArquivosComunicacao/Desafios_ingles.pdf. Accessed $12 \mathrm{Feb}$ 2008.

Shneiderman, B.: Universal Usability - pushing human-computer interaction research to empower every citizen. In: Communications of the ACM, May 2000, vol. 43, no. 5 (2000).

Unesco. Towards knowledge societies: UNESCO world report (2005). Available at: http://publishing.unesco.org/default.asp. Accessed 12 Feb 2008.

Varian, H. R.: Universal Access to Information. In: Communications of the ACM. October 2005, vol. 48, no 10 (2005).

World Bank, http://devdata.worldbank.org/external/CPProfile.asp?PTYPE=CP\&CCODE=BRA (2006). Accessed 12 Feb 2008. 